\title{
Avanços no desenvolvimento tecnológico e status atual do cultivo de lagostas (Panulirus argus) do ovo ao tamanho comercial
}

\author{
Advances in tecnological development and present status of the \\ spiny lobster (Panulirus argus) from egg to commecial size
}

\author{
Marco Antonio Igarashi ${ }^{1}$
}

\begin{abstract}
Resumo
A proposta desta revisão é resumir as informações sobre os estudos do cultivo de lagosta vermelha (Panulirus argus). As lagostas espinhosas tornaram-se, desde o início de sua exploração, um produto marinho de relevante importância econômica para o Brasil. No entanto, é notória a ocorrência da sobrepesca e, para efeito de minimizar essa situação uma das soluções é o seu cultivo. A larvicultura de lagostas em condições laboratoriais é sobremodo difícil, devido ao alto grau de sensibilidade da larva. O primeiro cultivo completo da lagosta vermelha desde a eclosão até o estágio de puerulus ocorreu na Estação de Pesca na Prefeitura de Mie no Japão. Este resultado refletiu em um aumento na disponibilidade de informações para o cultivo em condições ótimas, tal como ótimos parâmetros ambientais, alimentação e o desenho do tanque. Ainda há uma significante quantidade de problemas a serem resolvidos antes de estabelecer o cultivo de filosomas em escala comercial. Estes desafios incluem o controle de doenças bacterianas e excessiva agregação das larvas, o uso de dietas preparadas tal como alimentos artificiais, e a redução de alto custo operacional. Além disso, as possibilidades para o presente são a exploração de juvenis de áreas densamente habitadas e a utilização de alimentos naturais como alimento para lagostas. Podemos concluir que é possível cultivar os juvenis de lagostas em sistemas de engorda.
\end{abstract}

Palavras-chave: Ciclo de vida, cultivo, filosoma, juvenil, lagosta espinhosa

\begin{abstract}
The purpose of this review is to sumarize the studies on culture of Caribbean spiny lobster (Panulirus argus). Spiny lobster became a highly valued marine organism, since then, have had a manifold increase over the years in Brazil. However, most fisheries are fully exploited, and one of the few ways to increase production is through aquaculture. Keeping the larval spiny lobster alive in the laboratory through these delicate stages is very difficult. The first complete culture of Caribbean spiny lobster from hatch to puerulus stage occurred at Mie Prefectural Fisheries Station in Japan. This result reflects the increasing availability of information on optimal culturing conditions, such as optimal environmental parameters, feeding, and tank design. Still, there are significant problems to overcome in the establishment of largescale culture of phyllosoma. These further challenges include the control of bacterial diseases and excessive aggregation of larvae, the use of prepared diets such as artificial foods, and the reduction of high operating costs. In addition possibilities for the present are exploitation of juveniles from densely populated areas and utilization of natural food resources as feed for the lobster. In conclusion it is possible farming juvenile spiny lobsters in growout system.
\end{abstract}

Key words: Life cycle, culture, phyllosoma, spiny lobster

\footnotetext{
PhD em Engenharia de Pesca pela Universidade Kitasato, Japão. Professor Associado do Departamento de Engenharia de Pesca da Universidade Federal do Ceará a disposição do Ministério da Pesca e Aquicultura. E-mail: igarashi@ufc.br; marco.igarashi@ mpa.gov.br
} 


\section{Introdução}

A lagosta espinhosa é um valioso crustáceo, atingindo cotações elevadas e sofrendo intensa pressão da pesca. O Palinuridae consta de 49 espécies (PHILLIPS; COBB; GEORGE, 1980), das quais aproximadamente 33 espécies sustentam a pesca comercial (WILLIAMS, 1988).

As lagostas espinhosas, principalmente da família Palinuridae, na sua maioria, são originárias da Austrália, Nova Zelândia, Cuba, Brasil, África do sul, Estados Unidos e México (BOWEN, 1980).

As lagostas do gênero Panulirus são encontradas principalmente nas regiões tropicais e subtropicais. Três espécies de lagostas espinhosas são comercialmente capturadas na costa do Brasil (Panulirus argus, P. laevicauda e P. echinatus), representando uma entrada de divisas da ordem de 50 a 60 milhões de dólares (GÓES, 2006). Entre as três espécies no Nordeste do Brasil, duas espécies desfrutam de grande importância econômica, a saber: a vermelha ( $P$. argus) e a cabo-verde $(P$. laevicauda) cujas capturas se fazem principalmente com o covo, também denominado manzuá, arte de pesca preconizada pelo IBAMA (IGARASHI, 2007), participando com $78 \%$ e $20 \%$ da produção total, respectivamente com o mercado internacional que absorve mais de $90 \%$ da produção total do país.

Devido ao aumento excessivo do esforço da pesca, observa-se há alguns anos o acentuado declínio na produção e exportação de lagostas. Uma das únicas formas de reverter esse quadro é aumentar a produção através da aquicultura, porém o grande entrave no cultivo comercial da lagosta é a dificuldade do crescimento e o longo período requerido das espécies nos seus estágios larvais. Ironicamente, sabe-se relativamente pouco sobre a história da sua vida larval ou o elo entre a origem larval e o estoque de adultos de $P$. argus (GOLDSTEIN; MATSUDA; BUTLER, 2006).
As lagostas tropical ( $P$. ornatus) e vermelha (Panulirus argus) são as melhores candidatas para aquicultura por terem o mais curto período de desenvolvimento larval, de 4 a 8 meses (ACOSTA; MATHEWS; BUTLER, 1997; CRUZ et al., 2001; DENNIS; PICHER; SKEWES, 2001) e rápido crescimento pós-larval (WILLIAMS, 2007).

O cultivo de lagostas tropicais, $P$. ornatus, de puerulus e juvenis capturados têm se tornado uma importante atividade econômica no Vietnam, e a exportação anual têm alcançado uma produção maior que 1000 toneladas por ano (TUAN; NHO; HAMBREY, 2000; HAIR; BELL; DOHERTY, 2003). Estatísticas recentes não publicadas de produção têm sido estimadas em 4.000 toneladas por ano (JOHNSTON et al., 2006). Preliminarmente as investigações em aquicultura comercial de $P$. argus em pequena escala, baseado na captura de puerulus, tem também iniciado recentemente no Caribe (POWER et al., 2005).

Assim sendo, considerando-se a importância econômica da lagosta para o Brasil e o acentuado declínio na sua captura e o fato de que são escassas as informações disponíveis sobre o seu cultivo no Brasil, nesse artigo, é realizada uma sinopse com informação disponível sobre o cultivo de lagostas, e é sugerido possíveis adaptações e inovações que podem ser úteis ao desenvolvimento final de unidades de produção comercialmente rentáveis, procurando somar informações e contribuir para o desenvolvimento da metodologia de cultivo de lagostas da espécie $P$. argus.

\section{Ocorrência}

A $P$. argus (Figura 1) atinge até $45 \mathrm{~cm}$, ocorre na Bermuda, costa leste dos EUA, desde a Carolina do Norte até a Flórida, Golfo do México, Antilhas, costa das Américas Central e do Sul até São Paulo (HOLTHUIS, 1946, 1961) (Figura 2). 


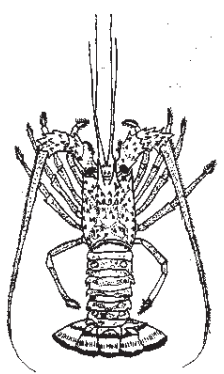

Figura 1. Panulirus argus (adaptado de MOE JÚNIOR, 1991)

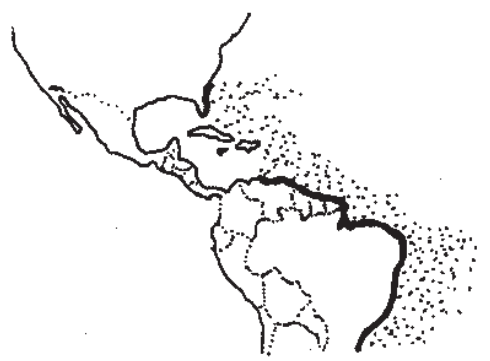

Figura 2. Distribuição da Panulirus argus (adaptado de WILLIAMS, 1988).

Habita principalmente os fundos de algas calcáreas da plataforma continental, em recifes, formações rochosas ou em locais que forneça abrigo. Pode ser encontrada até aproximadamente $90 \mathrm{~m}$ de profundidade, de hábitos predominantemente noturnos e gregários.

\section{Produção}

A lagosta $P$. argus sustenta uma das mais importantes capturas mundiais compreendendo aproximadamente $46 \%$ do total da captura de lagostas espinhosas (GOLDSTEIN; MATSUDA; BUTLER, 2006) com uma produção de 35.540 toneladas em 2005 (Figura 3).

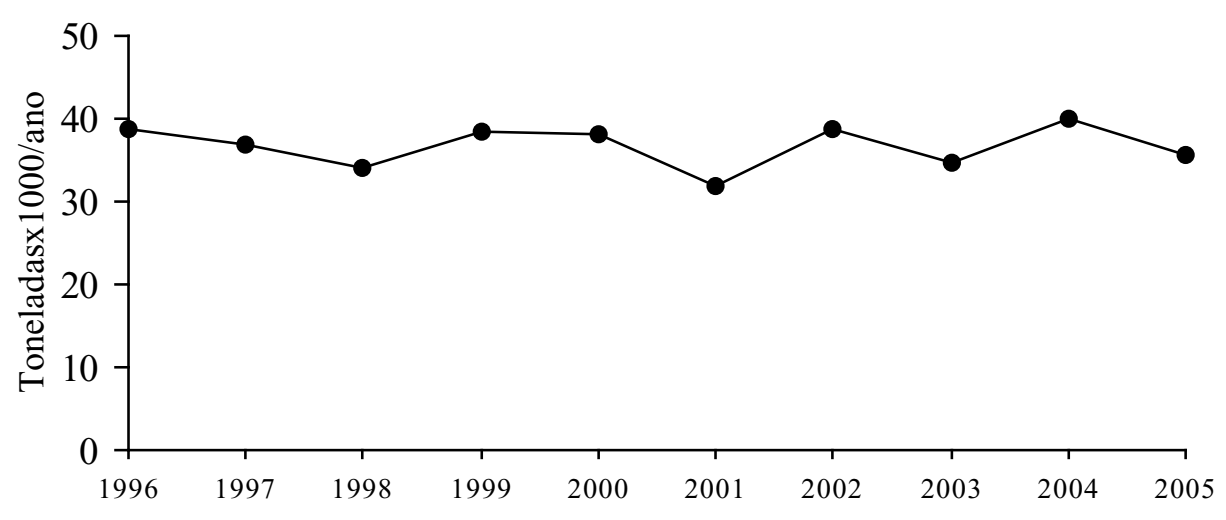

Figura 3. Produção mundial na captura de lagosta Panulirus argus.

Fonte: FAO (2008) 
Economicamente, a lagosta Panulirus argus e $P$. laevicauda são as espécies que sustentam a pesca comercial no Brasil. Ressalta-se, ainda, que a região nordeste é a principal produtora do referido crustáceo, cuja produção majoritária cabe geralmente ao Estado do Ceará, as quais em 2005 orçaram em 2.970 toneladas (Figura 4).

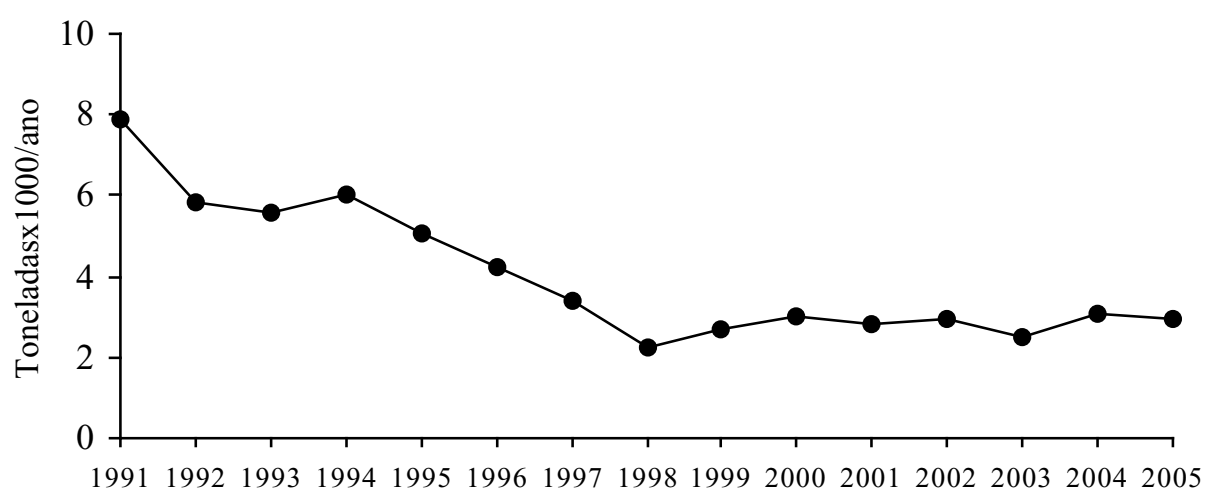

Figura 4. Produção de lagosta desembarcada no Estado do Ceará no período de 1991 a 2005. Fonte: IBAMA/ESTATIPESCA (2006)

A produção e a comercialização de lagostas $P$. argus não são consideradas estáveis, o que provoca uma oscilação nos preços no mercado. Entretanto a comercialização de lagostas tem sobrevivido ao mercado internacional, como também às variações da moeda corrente. O Brasil continuará sendo um competidor internacional neste setor.

\section{Ciclo de vida}

As lagostas $P$. argus possuem cinco grandes fases dentro do seu ciclo de vida: adulto, ovos, filosoma (estágios larvais), puerulus e juvenis (Figura 5) (MOE JÚNIOR, 1991; IGARASHI; MAGALHÃES NETO, 1999; PHILLIPS; KITTAKA, 2000; IGARASHI, 2007).

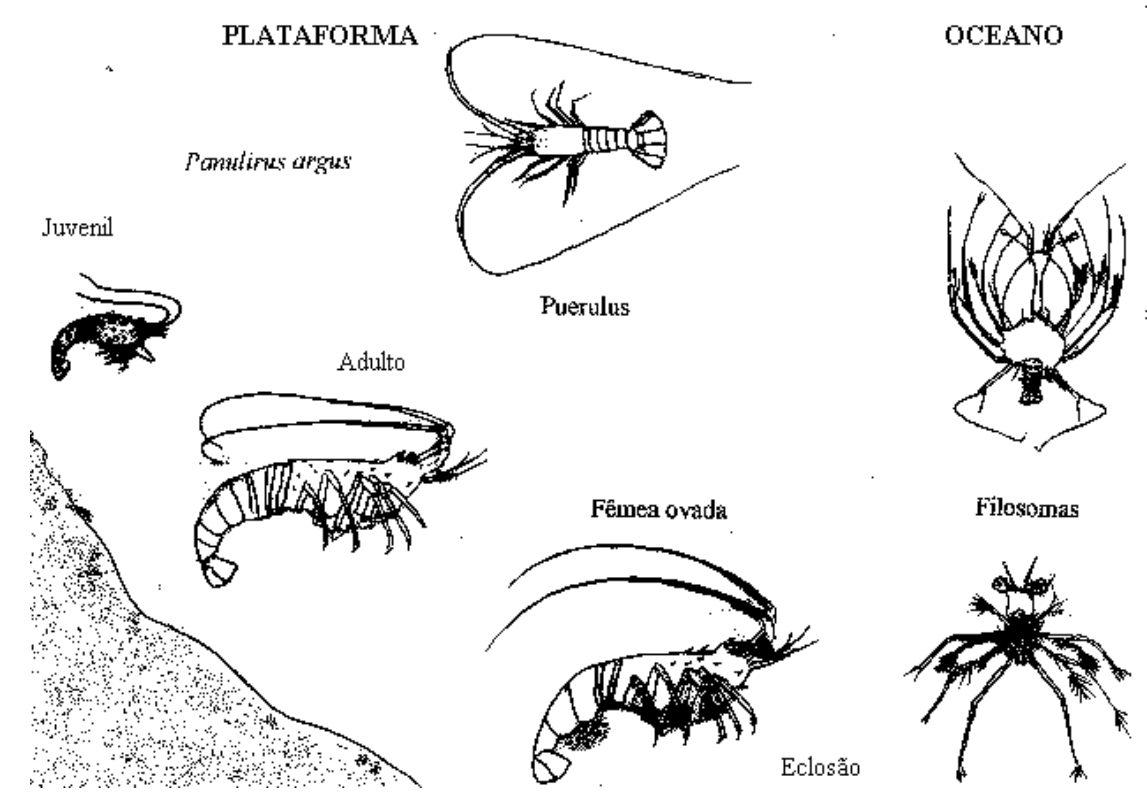

Figura 5. Ciclo de vida da lagosta Panulirus argus . 
Relativamente às atividades reprodutivas, podese estabelecer que começam quando elas atingem um comprimento total acima de $16 \mathrm{~cm}$. Quanto à desova, pode ocorrer durante o ano inteiro.

A reprodução ocorre após a muda das fêmeas e a desova pode ocorrer duas ou mais vezes ao ano. Os óvulos são liberados após a cópula.

Os ovos são subsequentemente incubados na parte inferior do abdômen da fêmea por um período de 3 a 5 semanas, dependendo, sobretudo, da temperatura da água, sendo que em temperaturas mais elevadas o tempo de incubação pode diminuir. Quando os ovos eclodem, acredita-se que a liberação das larvas ocorre primariamente em águas profundas.

Aspequenaslarvashabitamooceano, circunscritos a um período de até, aproximadamente, um ano, passando por um grande número de mudas até atingir a forma bentônica. Nessa fase as larvas filosomas completam a fase larval e, metamorfoseiam-se em um estágio transicional conhecido por puerulus, que, por sua vez, deslocam-se para o litoral, refugiandose isoladamente, em locais rasos, áreas de recifes, substratos de algas, etc. Eles tendem a se tornar mais gregários com o crescimento e começam a se reunir em locas, formações rochosas, etc. Por seu turno, os juvenis de mais idade migram sempre destas áreas, denominadas berçários, para locais mais profundos.

\section{Reprodução}

O $P$. argus atinge a maturidade sexual com o comprimento da carapaça de aproximadamente 70 - 80 mm (WITHAM; INGLE; JOYCE, 1968; OLSEN; KOBLICK, 1975). O P. argus acasala em poucos dias a várias semanas ou meses após a muda (PHILLIPS; COBB; KITTAKA, 1994). $\mathrm{O}$ acasalamento ocorre com o macho e a fêmea mantendo juntos os esternos e assim ocorre a liberação do espermatóforo o qual adere no esterno da fêmea, e permanecerá até a hora da desova. O esperma pode ser viável por períodos tão longo como um mês (MARX; HERRNKIND, 1986). A desova ocorre quando as fêmeas dobram o abdômen sob a carapaça, abrindo o telson e urópodos assim como os pleópodos. Os ovos são protegidos no abdômen. A fertilização ocorre, quando as fêmeas arranham o espermatóforo para liberar os espermatozóides que fecundam os óvulos. Lyons et al. (1981) relataram que a desova começa quando a temperatura chega a $24{ }^{\circ} \mathrm{C}$ em áreas profundas de recife.

O tamanho mínimo de desova tem diminuído para a $P$. argus da Flórida, talvez devido a intensa pressão da pesca. Em 1922 foi relatado que o tamanho mínimo do cefalotórax das fêmeas que desovaram foi de $76 \mathrm{~mm}$ (CRAWFORD; SCHMIDT 1923). Pesquisas posteriores revelam fêmeas no estágio reprodutivo com tamanho da carapaça de 65 - $71 \mathrm{~mm}$ no Sul da Florida (WARNER; COMBS; GREGORY, 1977; LYONS et al 1981).

$\mathrm{Na}$ Florida na primavera e verão os machos e fêmeas adultos são frequentemente encontradas em locais profundos, onde ocorre a desova (DAVIS 1975; HERRNKIND, 1976; LYONS et al. 1981). No Brasil a reprodução ocorre durante o ano todo (IGARASHI, 2007) e pode ter várias desovas em um ano (SUTCLIFFE, 1952). Buesa (1969) relatou que algumas fêmeas de $P$. argus têm duas desovas em uma estação sem uma muda entre os dois ciclos de procriação. Desta forma, podemos concluir que o efeito de diferentes temperaturas pode induzir novamente as fêmeas à desovarem em uma estação do ano (IGARASHI, 1996).

$\mathrm{O}$ intervalo entre a cópula e a oviposição pode ser de alguns minutos a alguns dias. Os ovos são movimentados posteriormente e são retidas nas alongadas cerdas no endopodito dos pleópodos (KITTAKA; MACDIARMID, 1994).

A fecundidade varia com o tamanho do corpo. Durante o período de reprodução as fêmeas maturas com o comprimento do cefalotórax de $75 \mathrm{~mm}$ podem carregar 300.000 ovos (SQUIRES; RIVEROS, 1978), de 71-75 mm carregam aproximadamente 230.000 ovos; enquanto fêmeas com mais de 100 
mm carregam mais de 700.000 ovos (MOTAALVES; BEZERRA 1968). Os ovos são de coloração alaranjado brilhante e aproximadamente $1 \mathrm{~mm}$ em diâmetro (LEWIS, 1951). Porém há relatos de tamanhos menores em diâmetro. Elas permanecerão no local até eclodirem em aproximadamente 3 semanas. Vários dias antes de ocorrer a eclosão, os ovos ficam marrom escuro.

As larvas filosomas praticamente transparentes eclodem dos ovos e dispersam na coluna da água nas várias vezes que as fêmeas flexionam o abdômen. A muda normalmente pode ocorrer após a desova (WILLIAMS, 1984).

\section{Filosomas}

Após o período de incubação do ovo, eclode a larva denominada de filosoma (Figura 6) que se alimenta de animais planctônicos (MOE JÚNIOR, 1991).

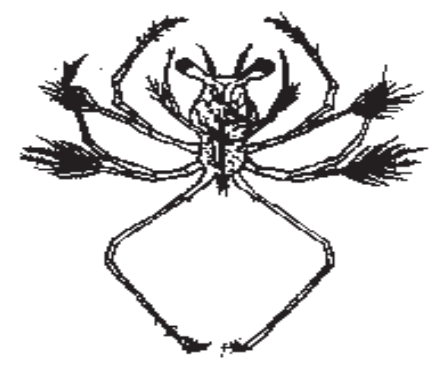

Figura 6. Larva filosoma

As larvas filosomas da lagosta são achatadas dorsoventralmente, animais praticamente transparentes, com grandes modificações para a existência planctônica (LEWIS, 1951), sendo transportados pelas correntes oceânicas por 6-12 meses antes da metamorfose para o estágio de pós-larva (LYONS et al., 1981). O tamanho inicial da larva pode ser de aproximadamente $2 \mathrm{~mm}$ de comprimento total (TL) após a eclosão. As larvas filosomas metamorfosearam após 18 - 21 mudas (média $=19,7)$ cultivados individualmente em sistema estático de água do mar a $25-27^{\circ} \mathrm{C}$ para o estágio de puerulus (GOLDSTEIN; MATSUDA; BUTLER, 2006). A larva filosoma por não praticar canibalismo, podem ser cultivadas juntas e ou individualmente. O tanque de cultivo de filosomas deve permitir que a larva permaneça em suspensão para não causar danos físicos. A perda de apêndices pela larva filosoma pode inibir a sua alimentação e a contrair infecções. Um tanque circular é o mais conveniente porque é mais efetivo para criar uma corrente circular com variações de velocidades para conservar a larva e o alimento flutuando.

O desenvolvimento das larvas filosomas é expresso pelo estágio e pelo instar. O estágio é determinado pela mudança morfológica e o instar relata o número de mudas. Baseado em amostras planctônicas, 11 estágios foram descritos para $P$. argus (LEWIS, 1951). Várias espécies possuem 11 estágios de filosoma. Sendo que cada estágio pode representar 1 ou mais instares. O número de instares também varia com a espécie. As espécies que vivem em temperatura fria tem menor número de instares comparada com as espécies que vivem em temperatura mais quentes.

O comprimento do corpo no estágio final de filosoma e de puerulus de $P$. argus variou de 25,60 - 28,20 mm (média $=27,00 \mathrm{~mm}$ ) e 16,40 - 17,50 $\mathrm{mm}$ comprimento do corpo $(\mathrm{BL})$ (média $=17,00$ $\mathrm{mm}$ ), respectivamente (GOLDSTEIN; MATSUDA; BUTLER, 2006).

Jiro Kittaka e sua equipe completaram o ciclo larval de várias espécies de lagostas utilizando como alimento náuplios de Artemia nos estágios iniciais e mexilhão Mytilus edulis nos estágios intermediários e finais (IGARASHI, 1996).

Um dos maiores obstáculos no cultivo comercial de lagostas $P$. argus é obter sobrevivência satisfatória para cultivo comercial em todo o seu ciclo larval, fato pelo qual o cultivo de lagostas espinhosas não tem ainda se desenvolvido em larga escala apesar de significantes avanços nas pesquisas. 


\section{Puerulus}

O estágio final das larvas filosomas metamorfoseiam para o estágio de puerulus, o qual é um estágio transicional do filosoma para o juvenil bentônico (KITTAKA, 2000). O puerulus é quase que transparente e morfologicamente é semelhante ao juvenil (Figura 7).
O puerulus aparentemente navega para o berçário de juvenis através do complexo sistema receptor formado pelo sistema de antenas e setas penado, e uma vez no berçário, o puerulus assenta em habitats selecionados (MIKAMI; KUBALA, 2004) e tendem permanecer poucos centímetro da superfície da água (LYONS, 1980).
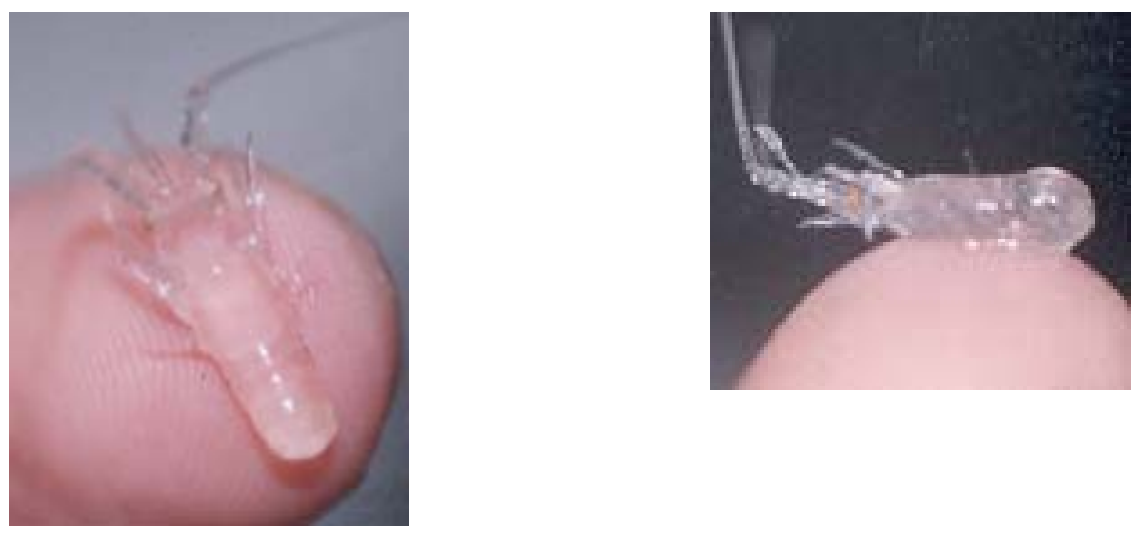

Figura 7. Pueruli de lagosta Panulirus argus.

Uma vez no berçário, os pueruli preferem assentar em um habitat de arquitetura complexa, podendo se assentar nos berçários de algas (WITHAM; INGLE; SIMS JÚNIOR, 1964), como a alga vermelha tal como a Laurencia (HERRKIND; JERNAKOFF; BUTLER, 1994). A preferência por estes habitats é mediada pela estrutura complexa e não pela disponibilidade de alimentos.

O puerulus de $P$. argus muda para o primeiro instar juvenil bentônico em um período mais curto no verão do que no inverno (FIELD; BUTLER, 1994; BUTLER; HERRNKIND, 2000). Os pueruli persistem por várias semanas, não se alimentam e são oceânicos (LYONS, 1980; HERRKIND;
BUTLER,1986; KITTAKA, 2000). Segundo Goldstein, Matsuda e Butler, (2006) em cativeiro as lagostas $P$. argus foram cultivadas desde o ovo até puerulus em 140 a 198 dias (média $=173,8$ dias) em temperaturas entre 25 e $27^{\circ} \mathrm{C}$.

Progressos no cultivo até o estágio de puerulus têm sido realizados para várias espécies de lagostas, mas somente um pequeno número de puerulus de $P$. argus têm sido produzido em laboratório.

Vários dias após o estágio de puerulus, ocorre a primeira muda para o estágio de juvenil (Figura 8), e começam a se pigmentar, com a coloração vermelho marrom. Os juvenis mais jovens tendem a ser solitário e comportam-se agressivamente. 


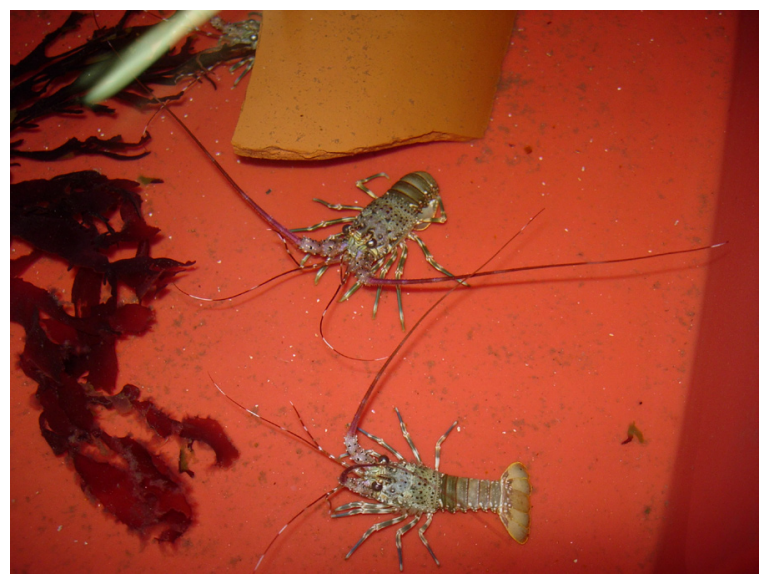

Figura 8. Juvenis de lagosta Panulirus argus.

\section{Juvenis e adultos}

A taxa de crescimento de machos e fêmeas de $P$. argus nas áreas de berçário são aproximadamente iguais no sul da Florida (DAVIS; DODRILL 1989). Por outro lado Little (1972) e Olsen e Koblick (1975) relataram que as fêmeas tendem a crescer mais devagar que os machos.

Witham, Ingle e Joyce (1968) cultivou lagostas de $P$. argus desde puerulus sob condições de laboratório até 7 meses. Durante este período os indivíduos com media de $6 \mathrm{~mm}$ de comprimento de cefalotórax cresceu até a uma média de $34 \mathrm{~mm}$, com a taxa de crescimento variando de 3,8-4,2 $\mathrm{mm}$ por mês. Outras populações em laboratório cresceram mais lentamente, com Lewis, Moore e Babis (1952) e Sweat (1968) relatando taxa de crescimento mensal menores do que $2 \mathrm{~mm}$ por mês. Assumindo que após o assentamento a taxa de crescimento é de 4,0 mm por mês, a $P$. argus parece chegar ao tamanho legal de captura em 20 - 40 meses (LITTLE, 1972; DAVIS; DODRILL, 1989). Eldred, Futch e Ingle (1972) estimou uma taxa média de crescimento da população selvagem de $P$. argus de $5 \mathrm{~mm}$ por mês para os primeiros 9-10 meses após o assentamento na Florida. Durante o desenvolvimento da lagosta, quanto maior a lagosta menor a frequência de mudas (Tabela 1).

Tabela 1. Crescimento e frequência de muda da lagosta Panulirus argus cultivado em laboratório.

\begin{tabular}{lccc}
\hline Peso inicial (g) & Período de cultivo (meses) & Peso final médio(g) & Número de mudas \\
\hline $0,15-0,20$ & 2 & 1 & $3-4$ \\
$1-2$ & $3-4$ & 10 & $4-5$ \\
$10-20$ & $7-9$ & 100 & $4-6$ \\
100 & $7-10$ & 200 & $3-4$ \\
\hline $200-250$ & $10-15$ & $350-400$ & $2-4$ \\
\hline
\end{tabular}

Fonte: Igarashi (2005)

Segundo Booth e Kittaka (2000) a taxa diária de alimentação de juvenis médios e maiores está na faixa de $1-15 \%$ do peso corpóreo. De acordo com Brito e Diaz (1983) a conversão bruta é de 3,97:1 para juvenis de $P$. argus mantidos a $27^{\circ} \mathrm{C}$ e alimentados com moluscos. Quando cultivou-se a lagosta $P$. argus de pós-larva ao tamanho comercial a uma temperatura de 24,0 a $29,9^{\circ} \mathrm{C}$ (Figura 9), elas atingiram o peso de 370 gramas em 28 meses de cultivo (IGARASHI, 2007). 


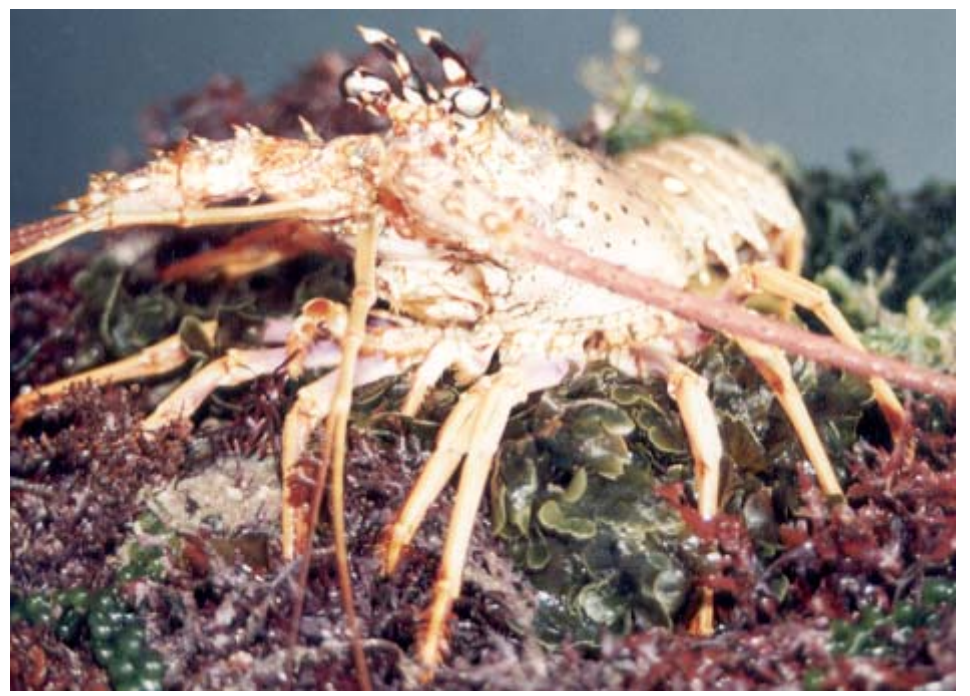

Figura 9. Lagosta adulta de Panulirus argus.

As lagostas juvenis podem mudar uma media de 2,5 vezes ao ano na Flórida (WILLIAMS, 1984). As características do crescimento são relacionadas com a idade, com a frequência de muda e incremento no crescimento na muda tendendo a diminuir com a idade (AIKEN 1980). A variação na qualidade e abundância de alimento, densidade da população, temperatura da água, assim como a taxa de predação e injuria, todos esses fatores afetam a taxa de crescimento da população local.

Embora as pesquisas demonstrem que os juvenis de lagostas $P$. argus têm, relativamente, uma ampla tolerância as condições ambientais; suas necessidades nutritivas e o seu crescimento os tornam apropriados para o cultivo; podem ser mantidos com êxito em sistemas convencionais de cultivo, a um custo mais módico; adaptam-se bem às condições artificiais e alimentares; se cultivados em temperaturas elevadas sua taxa de crescimento pode ser incrementada marcadamente, quando comparada com a dos juvenis em condições naturais.

\section{Conclusões}

Independentemente da forma como a lagosta $P$. argus é capturada, a probabilidade de ampliação das atividades vinculadas à pesca da lagosta é finita, devido às limitações bioecológicas naturais existentes. Em face dessa inevitabilidade, perspectivas estão se vislumbrando na aquicultura. No entanto devido a lagosta maturar e reproduzir em cativeiro e poder ser cultivadas juntas, fazem deste um crustáceo com potencialidade para o cultivo comercial provavelmente de médio a longo prazo. Porém poucos trabalhos foram realizados com o objetivo do cultivo em larga escala na produção comercial no Brasil.

Neste ponto de vista as informações técnicocientíficas são suficientes para avaliar uma iniciativa de um projeto piloto para a engorda de lagostas $P$. argus, embora o mais importante atualmente, seja o suprimento suficiente de puerulus e juvenis recentes para o cultivo comercial e o, desenvolvimento de dietas artificiais eficientes, procedimentos de métodos de cultivo em larga escala, com o intercâmbio de compra e venda. Isto também deve ser efetuado de forma simples e direta para confirmar a viabilidade comercial da engorda de juvenis no Brasil.

Porém os maiores problemas enfrentados não somente no Brasil para o sucesso dos projetos de engorda de lagostas são os longos períodos para o retorno do investimento. Por outro lado uma boa base financeira parece ter sido recebida pelos japoneses, 
graças ao qual tem conseguido realizar enormes progressos no desenvolvimento da metodologia de cultivo de lagostas.

\section{Agradecimentos}

Agradeço ao Professor Jiro Kittaka (Universidade de Ciência de Tokyo) pelas informações fornecidas sobre o cultivo de lagostas.

\section{Referências}

ACOSTA, C. A.; MATTHEWS, T. R.; BUTLER, M. J. Temporal patterns and transport processes in recruitment of spiny lobster (Panulirus argus) postlarvae to south Florida. Marine Biology, Florida, v. 129, n. 1, p. 79-85, 1997.

AIKEN, D. E. Molting and growth. In: COBB, J. S.; PHILLIPS, B. F. (Ed.). The biology and management of lobsters. New York: Academic Press, 1980, p. 91-147. v. 1.

BOOTH, J. D.; KITTAKA, J. Spiny lobster growthout. In: PHILLIPS, B. F., KITTAKA, J. (Ed.). Spiny Lobster: fiheries and culture. Oxford: Fishing News Books, 2000. p. 556-585.

BOWEN, B. K. Spiny lobster management. In: COBB, J. S.; PHILLIPS, B. F. (Ed.). The biology and Management of Lobsters, New York, USA: Academic Press, 1980. p. 243-264.

BRITO, P. R. E.; DIAZ, E. I. Observaciones sobre el consumo de alimento y su efecto sobre el crescimento en juveniles de langosta Panulirus argus en el laboratório. Revista de Investigaciones Marinas, Habana, v. 4, n. 2, p. 75-89, 1983.

BUESA, R. J. Langosta comun Panulirus argus (Latreille) hacia nuevos objetivos en su investigation. Mar y Pesca, Cuba, v. 46, n. 1, p. 5-11, 1969.

BUTLER, M. J. I. V.; HERRKIND, W. F. Puerulus and juvenile ecology. In: PHILLIPS, B. F.;;KITTAKA, J. (Ed.). Spiny lobster: fisheries and culture. London: Blackwell Scietific publications Fishing News Books, 2000, p. 276-301.

CRAWFORD, D. R.; SCHMIDT, W. J. J. The spiny lobster, Panulirus argus, of southern. Florida: its natural history and utilization. Bulletin United State Bureau Fisheries, USA, v. 38, n. 917, p. 281-310, 1923.

CRUZ, R.; DIAZ, E.; BAEZ, M.; ADRIANO, R.
Variability in recruitment of multiple life stages of the Caribbean spiny lobster, Panulirus argus, in the Gulf of Batabano, Cuba. Marine Freshwater Research, Collingwood, v. 52, n. 8, p. 1263-1270, 2001.

DAVIS, G. E. Minimum size of mature spiny lobsters, Panulirus argus, at Dry Tortugas, Florida. Transactions of the American Fisheries Societ, Bethesda, v. 104, n. 4, p. 675-676, 1975.

DAVIS, G. E.; DODRILL, J. W. Recreational fishery and population dynamics of spiny lobsters, Panulirus argus, in Florida Bay, Everglades National Park, 1977-1980. Bulletin of Marine Science, Wrentham, v. 44, n. 1, p. 7888, 1989.

DENNIS, D. M.; PITCHER, C. R.; SKEWES, T. D. Distribution and transport pathways of Panulirus ornatus (Fabricius, 1798) and Panulirus spp. larvae in the Coral Sea, Australia. Marine and Freshwater Research, Collingwood, v. 52, n. 8, p. 1175-1185, 2001.

ELDRED, B.; FUTCH, C. R.; INGLE, R. M. Studies of juvenile spiny lobsters, Panulirus argus, in biscayne bay, Florida. Special Science Report Saint Petersburg, Florida, v. 10, n. 35. p. 1-15, 1972.

FAO. Fisheries and Aquaculture Information and Statistics Service. Species fact sheets Panulirus argus (Latreille, 1804). Disponível em: $<\mathrm{http} / / \mathrm{www}$.fao. org/.../graphs/species/Capture/3445.gif $>$. Acesso em: 17 jan. 2008.

FIELD, J. M.; BUTLER, M. J. I. V. The influence of temperature, salinity, and postlarval transport on the distribution of juvenile spiny lobsters, Panulirus argus (Latreille, 1804) in Florida Bay. Crustaceana, Leiden, v. 67, n. 1, p. 26-45, 1994.

GÓES, C. A. Análise da dispersão de larvas de lagostas no atlântico tropical a partir de correntes geostróficas superficiais derivadas por satélites. 2006. Dissertação. (Mestrado em Sensoriamento Remoto) - INPE, São José dos Campos. Disponível em: <http://mtc-m17.sid.inpe. br/col/sid.inpe.br/MTC-m13@80/2006/07.10.14.12/doc/ publicacao.pdf $>$. Acesso em: 07 jul. 2007.

GOLDSTEIN, J.; MATSUDA, H.; BUTLER I. V. M. Success! Caribbean spiny lobster, Panulirus argus is cultured from egg to juvenile for the first time. The Lobster Newsletter, Norfolk, v. 19, n. 1, p. 3-5, 2006.

HAIR, C.; BELL, J. D.; DOHERTY, P. J. The use of wildcaught juveniles in coastal aquaculture and its application to coral reef fishes. In: STICKNEY, R. R.; MCVEY, J. P. (Ed.). Responsible marine aquaculture. Oxon: $\mathrm{CAB}$ International, 2003. p. 327-353.

HERRKIND, W. E.; BUTLER, M. J. Factors regulating 
post larval se ttlement and juvenile micro habtat use $\mathrm{Yb}$ spiny lobster Panulirus argus. Marine Ecology Progress Series, Nordbunte, v. 28, n. 1, p. 23-30, 1986.

HOLTHUIS, L. B. Biological results of the snellius expedition 14. The decapoda macrura of the snellius expedition. I. The Stenopidae, Nephropsidae, Scyllaridae and Palinuridae. Temminckia, Leiden, v. 7, n. 1, p. 1-178, 1946.

HOLTHUIS, L. B. The taxonomic status of Panulirus echinatus smith. Decapoda, macrura, palinuridae. Crustaceana, Leiden, v. 2, n. 1, p. 223-227, 1961.

IBAMA - ESTATIPESCA. Estatística da pesca do IBAMA. 2006. Disquete.

IGARASHI, M. A. Cultivo de larva de lagosta-filosoma. Fortaleza: SEBRAE, 1996. 48p.

. Cultivo de lagosta Panulirus argus de pós-larva ao tamanho comercial. In SOUZA, R. A. L.; IGARASHI, M. A.; PENAFORT, J. M. Práticas elementares na aqüicultura marinha. Belém: Universidade Federal Rural da Amazônia, 2005, p. 73-98.

Sinopse da situação atual, perspectivas e condições de cultivo para lagostas palinuridae. Ciência Animal Brasileira, Goiânia, v. 8, n. 2, p. 155-166, 2007.

IGARASHI, M. A.; MAGALHÃES NETO, E. O. O ciclo de desenvolvimento e a situação atual do cultivo de lagostas no Brasil e no mundo. Revista Econômica do Nordeste, Fortaleza, v. 30, n. 1, p. 94-99, 1999.

IGARASHI, M. A. Sinopse da situação atual, perspectivas e condições de cultivo para lagostas Palinuridae. Ciência Animal Brasileira, Goiânia, v. 8, n. 2, p. 155-166, 2007.

JOHNSTON, D.; MELVILLE-SMITH, R. M.; HENDRIKS, B.; MAGUIRE, G. B.; PHILLIPS, B. Stocking density and shelter type for the optimal growth and survival of western rock lobster Panulirus cygnus (George). Aquaculture, Amsterdam, v. 260, n. 1/4, p. 114-127, 2006.

KANCIRUK, P.; HERRNKIND, W. F. Autumnal reproduction of spiny lobster, Panulirus argus, at Bimini, Bahamas. Bulletin of Marine Science, Wrentham, v. 26, n. 4, p. 417-432, 1976.

KITTAKA, J.; MACDIARMID, A. B. Breeding. In: PHILLIPS, B. F.; COBB, J. S., KITTAKA, J. (Ed.). Spiny lobster management. London: Fishing News Books. 1994, p. 385-401.

KITTAKA, J. Culture of larval spiny lobsters. In: PHILLIPS, B. F.; J. KITTAKA, J. (Ed.) Spiny lobster: fisheries and culture. London: Fishing News Books, Blackwell Scientific Publications. 2000, p. 508-532.
LEWIS, J. B. The phyllosoma larvae of the spiny lobster Panulirus argus. Bulletin of Marine Science Gulf Caribean, Miami, v. 1, n. 2, p. 89-103, 1951.

LEWIS, J. B.; MOORE, H. B.; BABIS, W. Post-larval stages of the spiny lobster Panulirus argus Bulletin of Marine Science, Wrentham, v. 2, n. 1, p. 324-337, 1952.

LITTLE, E. J. Tagging of spiny lobsters (Panulirus argus) in the Florida Keys, 1967-69. Special Science Report Saint Petersburg, Florida, n. 31, 23 p. 1972.

LYONS, W. G.; BARBER, D. G.; FOSTER, S. M.; KENNEDY JÚNIOR, F. S.; MILANO, G. R. The spiny lobster, Panulirus argus, in the middle and upper Florida Keys: population structure, seasonal dynamics, and reproduction. Florida Marine Research Publications, Florida, v. 10, n. 38. p.1-38, 1981.

LYONS, W.G. The postlarval stage of scyllaridean lobsters. Fisheries, Bethesda, v. 5, n. 4, p. 47-49, 1980.

MARX, J. M.; W. F. HERRNKIND, W. F. Species profiles: life histories and environmental requirements of coastal fishes and invertebrates (south Florida)-spiny lobster. U.S. Fish Wildl. Service Biology Report. 82(11.61). U.S. Army Corps of Engineers Technical Report, TR EL-82-4. Washington: Wetlands 1986, $21 \mathrm{p}$.

MIKAMI, S.; KUBALLA, A. Overview of lobster aquaculture research. Proceeding The Second Hatchery Feeds And Technology Workshop, Sydney, v. 1, n. 1, p. 127-130, 2004.

MOE JUNIOR, M. A. Lobsters: Florida, Bahamas, the Caribbean. Haleiwas: Green Turtle Publications, 1991, $510 \mathrm{p}$.

MOTA-ALVES, M. I.; BEZERRA, R. C. F. Sobre o número de ovos da lagosta Panulirus argus (Latr.). Arquivo Estação de Biologia Marinha da Universidade Federal do Ceará, Fortaleza, v. 8, n. 1, p. 33-35, 1968.

OLSEN, D. A.; KOBLICK. I. G. Population dynamics, ecology, and behavior of spiny lobster, Panulirus argus, of St. John, U.S. Virgin Islands: growth and mortality. Results of the Tektite program, v. 2. Natural History Museum Los Angeles Cty. Science Bulletin, Los Angeles, v. 20, n. 1, p. 17-21, 1975.

PHILliPS, B. F.; COBB, J. S.; KITTAKA, J. Spiny lobster management. London: Fishing News Books, Blackwell Scientific Publications, 1994, 550 p.

PHILLIPS, B. F.; COBB, J. S.; GEORGE, R. W. General biology. In: COBB, J. S.; PHILLIPS, B. F. (Ed.). The biology and management of lobsters. New York: Academic Press, 1980, p. 1-82. 
PHILLIPS, B. F.; KITTAKA, J. Spiny lobster: fisheries and culture. London: Blackwell Scietific Publications Fishing News Books, 2000. 679 p.

POWER, R.; MUNRO, J. L.; DIFFENTHAL, M.; LANE, G. Preliminary investigations into the feasibility of small scale, commercial aquaculture of Panulirus argus, based on collection of pueruli from the wild. Proceeding 56th Gulf and Caribean Fisheries Institute, Miami, v. 56, n. 1, p. 233-248, 2005.

SQUIRES, H. J.; RIVEROS, G. Fishery biology of spiny lobsters Panulirus argus of the Guajira Peninsula of Colombian South America 1969-1970. Proceeding Natural Shelfish. Association, Washington, v. 68, n. 1, p. 63-74, 1978.

SUTCLIFFE, W. H. Some observations of the breeding and migration of the Bermuda spiny lobster, Panulirus argus. Proceedings of the Gulf and Caribbean Fisheries Institute, Miami, v. 4, n. 1, p. 64-69, 1952.

SWEAT, D. E. Growth and tagging studies on Panulirus argus (Latreille) in the Florida Keys. Marine Research Laboratory Technical Publication, Florida, v. 1, n. 57, 30 p. 1968.

TUAN, L. A.; NHO, N. T.; HAMBREY, J. Status of cage mariculture in Vietnam. In: LIAO, I. C.; LIN, C. K. (Ed.). Cage culture in Asia. Proceedings of the First
International Symposium on Cage Culture in Asia. Asian Fisheries Society and World Aquaculture Society South-east Asia Chapter: Manila and Bangkok, 2000. p. 111-123.

WARNER, R. E.; COMBS, C. L.; GREGORY, D. R. Biological studies of the spiny lobster. Panulirus argus (Decapoda: Palinuridae) in south Florida. Proceedings of the Gulf and Caribbean Fisheries Institute, Miami, v. 29, n. 1, p. 166-183, 1977.

WILliAMS, A. B. Shrimps, lobsters, and crabs of the atlantic coast of the eastern United States. Washington, D.C. USA, Maine to Florida: Smithsonian Institution Press, 1984. 550p.

. Lobster of the world-an illustrated guide. New York: Osprey Books, 1988. 186 p.

WILLIAMS, K. C. Nutritional requirements and feeds development for post-larval spiny lobster. Aquaculture, Amsterdam, v. 263, n. 1/4, p. 1-14, 2007.

WITHAM, R.; INGLE, R. M.; SIMS JÚNIOR, H. W. Notes on postlarvae of Panulirus argus. Quaterly Journal Florida Academic Science, Florida, v. 27, n. 4, p. 289297, 1964.

WITHAM, R.; INGLE, R. M.; JOYCE, E.A. Physiological and ecological studies of Panulirus argus from the St. Lucie Estuary, State of Florida. Board of Conservation TechSer, Florida, v. 1, n. 53, 1968. 